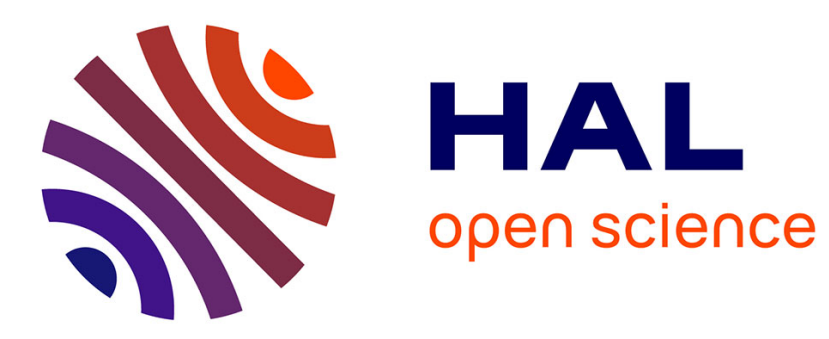

\title{
The equilibrium shape of nickel
}

Hila Meltzman, D. Chatain, Dan Avizemer, T.M. Besmann, W.D. Kaplan

\section{To cite this version:}

Hila Meltzman, D. Chatain, Dan Avizemer, T.M. Besmann, W.D. Kaplan. The equilibrium shape of nickel. Acta Materialia, 2011, 59 (9), pp.3473-3483. 10.1016/j.actamat.2011.02.021 . hal-00603250

\section{HAL Id: hal-00603250 https://hal.science/hal-00603250}

Submitted on 18 Apr 2018

HAL is a multi-disciplinary open access archive for the deposit and dissemination of scientific research documents, whether they are published or not. The documents may come from teaching and research institutions in France or abroad, or from public or private research centers.
L'archive ouverte pluridisciplinaire HAL, est destinée au dépôt et à la diffusion de documents scientifiques de niveau recherche, publiés ou non, émanant des établissements d'enseignement et de recherche français ou étrangers, des laboratoires publics ou privés. 


\section{Elsevier Editorial System(tm) for Acta Materialia Manuscript Draft}

Manuscript Number: A-11-124R1

Title: The Equilibrium Crystal Shape of Nickel

Article Type: Full Length Article

Keywords: Surface Energy; Nickel; Surface Segregation; Equilibrium Crystal Shape; Surface Anisotropy; Atom Probe Tomography

Corresponding Author: Prof. Wayne D. Kaplan, Ph.D.

Corresponding Author's Institution: Israel Institute of Technology

First Author: Hila Meltzman

Order of Authors: Hila Meltzman; Dominique Chatain, PhD; Dan Avizemer, B.Sc.; Theodore M Besmann, PhD; Wayne D. Kaplan, Ph.D.

Abstract: The crystal shape of Ni particles, dewetted in the solid state on sapphire substrates, was examined as a function of the partial pressure of oxygen $(\mathrm{P}(\mathrm{O} 2))$ and iron content using scanning and transmission electron microscopy. The chemical composition of the surface was characterized by atom-probe tomography. Unlike other FCC equilibrium crystal shapes, the Ni crystals containing little or no impurities exhibited a facetted shape, indicating large surface anisotropy. In addition to the $\{111\},\{100\}$ and $\{110\}$ facets, which are usually present in the equilibrium crystal shape of FCC metals, high index facets were identified such as $\{135\}$ and $\{138\}$ at low $P(02)$, and $\{012\}$ and $\{013\}$ at higher $\mathrm{P}(02)$. The presence of iron altered the crystal shape into a truncated sphere with only facets parallel to denser planes. The issue of particle equilibration is discussed specifically for the case of solid-state dewetting. 


\title{
The Equilibrium Crystal Shape of Nickel
}

Hila Meltzman ${ }^{\mathrm{a}}$, Dominique Chatain ${ }^{\mathrm{b}}$, Dan Avizemer ${ }^{\mathrm{a}}$, Theodore M. Besmann ${ }^{\mathrm{c}}$, and Wayne D. Kaplan ${ }^{\mathrm{a}}$

${ }^{a}$ Department of Materials Engineering, Technion - Israel Institute of Technology, Technion City, Haifa 32000, Israel

${ }^{b}$ CNRS, Aix-Marseille University, CINAM-UPR3118, Campus de Luminy, Case 913, 13288 Marseille cedex 09

${ }^{c}$ Material Science \& Technology Division, Oak Ridge National Laboratory, Oak Ridge, TN 37831, USA.

Keywords: Surface Energy; Ni; Surface Segregation; Equilibrium Crystal Shape; Surface Anisotropy; Atom Probe Tomography.

\begin{abstract}
The crystal shape of Ni particles, dewetted in the solid state on sapphire substrates, was examined as a function of the partial pressure of oxygen $\left(\mathrm{P}\left(\mathrm{O}_{2}\right)\right)$ and iron content using scanning and transmission electron microscopy. The chemical composition of the surface was characterized by atom-probe tomography. Unlike other FCC equilibrium crystal shapes, the Ni crystals containing little or no impurities exhibited a facetted shape, indicating large surface anisotropy. In addition to the $\{111\},\{100\}$ and $\{110\}$ facets, which are usually present in the equilibrium crystal shape of FCC metals, high index facets were identified such as $\{135\}$ and $\{138\}$ at low $\mathrm{P}\left(\mathrm{O}_{2}\right)$, and $\{012\}$ and $\{013\}$ at higher $\mathrm{P}\left(\mathrm{O}_{2}\right)$. The presence of iron altered the crystal shape into a truncated sphere with only facets parallel to denser planes. The issue of particle equilibration is discussed specifically for the case of solid-state dewetting.
\end{abstract}




\section{Introduction}

The correlation of surface energy anisotropy with the equilibrium crystal shape was extensively studied over the last century, since the foundations were laid by G. Wulff [1]. An understanding of surface energy anisotropy is important for many technological applications as well as for fundamental scientific reasons, including facet formation, crystal nucleation and growth, catalytic processes, thin films, surface step energy, and surface thermodynamics.

The equilibrium crystal shape (ECS) or Wulff shape of a crystal is the shape reflecting a minimum surface energy $[1,2]$. The normal vectors $R_{i}$ extending from the geometric center (Wulff point) to the surface facets can be used to calculate the relative surface energies $\left(\gamma_{\mathrm{i}}\right)$, according to:

$$
\frac{\gamma_{1}}{R_{1}}=\frac{\gamma_{2}}{R_{2}}=\ldots=\frac{\gamma_{i}}{R_{i}}=\text { const. } \Rightarrow \frac{\gamma_{i}}{\gamma_{j}}=\frac{R_{i}}{R_{j}}
$$

Equilibrated metal particles were previously used to study the surface energy anisotropy of several FCC metals such as $\mathrm{Cu}[3,4], \mathrm{Pb}[5,6]$ and $\mathrm{Au}[4,5,7,8$,$] . In most cases, at$ temperatures close to the melting point, the equilibrium (Wulff) shape of the pure metals was found to be composed of the close packed planes $\{111\}$ and $\{100\}$, connected by extended rough surfaces. An exception was $\mathrm{Cu}$ which also exhibits (smaller) $\{110\}$ and $\{311\}$ facets. At lower temperatures, it is difficult to reach the ECS because of kinetic limitations (time-size-evaporation), while the kinetic shape can indicate which facets are stable at lower temperatures $[9,10]$.

The discrepancies between experimentally determined ECSs of pure metals may be related to the adsorption/segregation of extra components to the surface, originating as either an original solute in the metal, adsorbed from the gas phase, or obtained from the substrate on which the crystals were equilibrated. Adsorption of one or several foreign species may take place at the metal surface and can have a significant influence on the anisotropy (and consequently on the ECS) [11,12,13,14]. The relation between adsorption and the change in surface free energy, $\gamma$ is described by the Gibbs adsorption isotherm: 


$$
\mathrm{d} \gamma=-\Sigma\left(\Gamma_{\mathrm{i}} \mathrm{d} \mu_{\mathrm{i}}\right)
$$

where $\Gamma_{\mathrm{i}}$ and $\mu_{\mathrm{i}}$ are the chemical surface excess and the chemical potential of component $i$, respectively. It is important to emphasize that it is not the concentration but rather the chemical potential of the solute which is correlated to surface adsorption, driven by a decrease in surface energy. This is a key-point in the case of oxygen adsorption at the surface of metals, which may take place at very low oxygen partial pressures, as directly measured for liquid metals [15], or at very low solute concentrations $[16,17]$.

While adsorption can significantly change the ECS (i.e. the surface anisotropy), very few experiments have been conducted on this topic [14]. One of the reasons is that a very low concentration of alloy components can have a strong effect and it is often difficult to control the composition of dilute alloys [12]. As such, careful control of the experimental conditions together with chemical analysis of the surface(s) is essential for characterization of the ECS. This is especially true for $\mathrm{Ni}$, due to its high surface energy which acts as a driving force for surface segregation $[12,18]$, and the relatively high annealing temperature required for equilibration compared to other metals. The difficulty in achieving pure and equilibrated $\mathrm{Ni}$ particles could be the reason why the ECS of Ni was not studied to the same extent as other FCC metals. Recently, the ECS of dewetted Ni particles was investigated by Hong et al. [19]. Surprisingly, they found that at equilibrium, the most stable surface is $\{210\}$ (which is usually the highest low index surface energy for FCC metals [12]), followed by $\{110\},\{111\},\{100\}$ and $\{320\}$. In these experiments, the initial $\mathrm{Ni}$ film contained a total of $100 \mathrm{ppm}$ of impurities, to which Si resulting from the use of a quartz tube furnace was added. No chemical analysis was performed on the equilibrated particles. In our opinion the ECSs of Ni determined by Hong et al. was modified by adsorption.

Mykura used the geometry of twin-boundary grooves in Ni annealed for 50-100 hours at $1273 \mathrm{~K}(0.75 \mathrm{Tm})$ in vacuum to experimentally determine surface anisotropy and found that the lowest energy surface was for $\{100\}$, followed by $\{111\}$ ( $\left.\chi_{(10)} / \mathcal{X}_{111)}=0947 \pm 00 \mathbb{X}\right)[20]$. The maximum anisotropy found at this relatively low 
equivalent temperature was $8.5 \pm 2 \%$. The purity of the Ni sheets was not reported, nor was the vacuum level (partial pressure of oxygen) used for annealing. While the measured anisotropy was consistent with the expected increase of anisotropy with temperature [11], the lack of surface chemical analysis prevents any comparison of Mykura's results with similar experiments. Sundquist used Ni particles equilibrated on $\mathrm{BeO}$ for up to 100 hours at $1273 \mathrm{~K}$ to investigate the Wulff shape in two different atmospheres: vacuum and dry $\mathrm{H}_{2}$ [4]. Although no quantitative measurement of the anisotropy was made, $\{111\}$ and $\{100\}$ facets were identified in both atmospheres. However, the particles equilibrated in vacuum had almost no rounded surfaces and were almost completely faceted, while the particles equilibrated in $\mathrm{H}_{2}$ had rounded surfaces with sharp edges connecting the facets. The authors attributed this difference to anisotropic $\mathrm{O}_{2}$ or $\mathrm{H}_{2}$ adsorption, respectively (although $\mathrm{H}_{2}$ does not adsorb on the surface of $\mathrm{Ni}$ at this temperature [21]). No surface analysis was done to validate this assumption. In another report, Barsotti et al. investigated the ECS of a Ni field emission tip at $1300 \mathrm{~K}$ and were able to measure the anisotropy of low index facets as well as rounded surfaces [22]. Emphasis was made on the measurement of surface impurities and only tips that were found to have clean surfaces were investigated. However, due to the initial geometry of the tips the resulting shape may have not been the equilibrium shape but rather that correlated with steady state, and thus only the facets at the apex were investigated. Barsotti et al. determined that the $\{111\}$ facet has the lowest energy, followed by $\{001\}$, and a maximum anisotropy of $3 \%$.

In addition to surface composition, temperature also has a significant influence on surface anisotropy [11]. Moreover, the driving force for surface adsorption is also temperature dependent $[14,17]$.

In this work, the equilibrium shape of $\mathrm{Ni}$ was investigated in two different atmospheres: Ar and $\mathrm{Ar}+7 \% \mathrm{H}_{2}$. In addition, the influence of Fe on the ECS was also studied. The crystal shapes were determined using transmission electron microscopy (TEM), and high resolution scanning electron microscopy (HRSEM) and compared with simulated Wulff shapes [3]. A detailed chemical analysis of the equilibrated surfaces was conducted using atom probe tomography (APT). 


\section{Experimental Procedures}

\section{Dewetting Experiments}

(0001) oriented sapphire $\left(\alpha-\mathrm{Al}_{2} \mathrm{O}_{3}\right)$ substrates of $99.99 \%$ purity were provided by Gavish Industrial Technologies \& Materials (Omar, Israel). Substrates were ultrasonically cleaned in acetone and ethanol. Ni films (120-250 nm thick) were deposited on the substrates by magnetron sputtering or by e-beam deposition $(99.99 \%$ and 99.9995\% pure, respectively). The specimens were dewetted [23] and further annealed in the solid state (between at 1572-1623 K) to form a large number of particles with a diameter ranging from $100 \mathrm{~nm}$ to a few microns (see Table 1), and were cooled at a rate of $15-20 \mathrm{~K} / \mathrm{min}$.

Three different annealing procedures were performed in order to examine the influence of $\mathrm{P}\left(\mathrm{O}_{2}\right)$ and the purity of the Ni particles on the equilibrium shape. In all cases, the total pressure was at least one order of magnitude larger than the vapor pressure of $\mathrm{Ni}$ (to limit evaporation) and the $\mathrm{P}\left(\mathrm{O}_{2}\right)$ levels were below the threshold for $\mathrm{Ni}$ oxidation or Ni-spinel formation (i.e. $\mathrm{P}\left(\mathrm{O}_{2}\right)<3 * 10^{-9} \mathrm{~atm}$.) [24]. The experimental conditions in which the three specimens were prepared (marked here after as systems A, B, C) are given in Table 1.

\section{Characterization Methods}

The morphology of the equilibrated $\mathrm{Ni}$ particles was examined by high resolution scanning electron microscopy (HRSEM, FEI Strata 400-S). The Ni particle texture was also analyzed by X-ray diffraction (XRD), using $\mathrm{Cu} \mathrm{K} \alpha$ radiation operated at $40 \mathrm{~mA}$ and $40 \mathrm{kV}$ (Philips X'Pert goniometer). A $\theta-2 \theta$ coupled Bragg-Brentano geometry was used for analysis of integrated intensities and the preferred orientation of $\mathrm{Ni}$ reflections relative to the sapphire substrate.

A dual-beam focused ion beam (FIB, Strata $400 \mathrm{~s}$, FEI) equipped with a field emission gun (FEG) electron source (operated at 3-30 kV), a Ga ion beam (2-30 kV), an in-situ nanomanipulator (Omniprobe, AutoProbe 200) and a scanning transmission electron microscopy (STEM) detector was used for preparing TEM specimens from the center of particles with a known morphology and orientation using the in-situ "lift-out" technique 
$[25,26]$. The particles were sectioned across the Wulff center and in a direction carefully chosen to intersect specific surface facets. This was important for subsequent edge-on imaging of the facets by TEM. The particles were initially covered with a protective layer ( $\mathrm{Pt}$ or $\mathrm{C}$ ) deposited using the electron beam in the FIB, in order to prevent surface damage by the ion beam.

Particles for TEM specimen preparation and subsequent analysis were selected according to the following criteria:

1) Particle size: Since the shape evolution involves diffusion processes, only relatively small crystals at high homologous temperatures will be able to reach an equilibrium shape within a reasonable time-frame. The equilibration time $(\tau)$, for a particle with radius $r$ is given by [27]:

$$
\tau=\frac{r^{4} k T}{24 \gamma D_{s} v \Omega}
$$

where $\mathrm{k}$ is Boltzmann's constant, $\mathrm{T}$ is the absolute temperature, $\gamma$ is the surface energy $\left(<2.1 \mathrm{~J} / \mathrm{m}^{2}[18]\right), \mathrm{D}_{\mathrm{s}}$ is the surface diffusivity $\left(5^{*} 10^{-12} \mathrm{~m}^{2} / \mathrm{s}[28]\right), v$ is the number of atoms per unit surface area, and $\Omega$ is the atomic volume. Given these values it was calculated that under the experimental conditions used here, only particles smaller than $1 \mu \mathrm{m}$ can be equilibrated, and the selected particles were usually much smaller.

2) Particle orientation and sectioning direction: The selected $\mathrm{Ni}$ particles were positioned in such a way that the sectioning direction was normal to the facet planes (and goes through the Wulff center of each particle). This allowed for edge-on imaging in the TEM, identification of the facets by electron diffraction, and correct measurement of surface energy anisotropy on a section of the Wulff shape.

3) Particle microstructure: Only single crystal particles, without grain boundaries, were selected and analyzed. 
The morphology of the particles was examined by TEM using a monochromated and aberration corrected FEG-TEM (FEI Titan 80-300 S/TEM) operated at $300 \mathrm{kV}$. Kikuchi electron diffraction was used to align the Ni particles in a low-index zone axis, with surface facets parallel to the viewing direction. After alignment of a Ni particle, selected area electron diffraction (SAD) patterns were acquired to identify the facet planes. The experimentally determined surface anisotropy and the Wulffman software were used to simulate the shape of the faceted spherical particles [29].

The composition of the surfaces was measured using atom probe tomography (APT, Imago, LEAP). Samples were prepared for APT using the dual-beam FIB following the procedure described in [30]. Experimentally determined APT bulk detection limits for $\mathrm{S}, \mathrm{Al}, \mathrm{Ar}, \mathrm{Fe}, \mathrm{Mo}, \mathrm{Ca}$, Si and $\mathrm{W}$ ranged from 25-35 ppm.

\section{Results}

\section{Ni Crystal Shape}

The preferred orientation of the Ni particles on (0001) sapphire was found to depend on the $\mathrm{P}\left(\mathrm{O}_{2}\right)$; a $\{100\}$ preferred orientation was dominant in system $\mathrm{A}\left(\mathrm{P}\left(\mathrm{O}_{2}\right)=10^{-9}\right.$ atm $)$ and a $\{111\}$ orientation was dominant in systems $B$ and $\mathrm{C}\left(\mathrm{P}\left(\mathrm{O}_{2}\right)<10^{-20}\right.$ atm). In both cases, the preferred orientation of the as-deposited film was $\{111\}$ (the preferred orientation was measured by XRD following the procedure described in [26]).

Figure 2 presents a HRSEM micrograph of one of the Ni particles equilibrated in Ar (system A, $\mathrm{P}\left(\mathrm{O}_{2}\right)=1 * 10^{-9}$ atm). This particle (with a (100) orientation parallel to the substrate surface) has a highly faceted shape. Four different families of facets are visible in the plan-view image, which have sharp connections to the rounded surfaces.

Figure 3 presents two HRSEM micrographs of a Ni particle equilibrated in $\mathrm{Ar}+\mathrm{H}_{2}$ (system $\mathrm{B}, \mathrm{P}\left(\mathrm{O}_{2}\right)<10^{-20} \mathrm{~atm}$ ). The particle is oriented with the (111) plane parallel to the substrate surface, and appears less faceted than the (100) oriented particle shown in Figure 2. However, this information cannot be used to draw any conclusions regarding the anisotropy of the surface energy for two reasons. First, the (111) oriented particle is coated with a thicker carbon layer that covers the morphological details on the surface, 
such as smaller facets. Second, the size of the (111) oriented particle is less than half that of the (100) oriented particle, so even if the facets were exposed, they might be too small to be detected (not resolved) by SEM. In addition, it is also possible that the connection of the facets to the rounded surface is smooth and not sharp as in system A. Such a gradual change in surface orientation (and thus contrast) makes facets much more difficult to detect.

Due to a concern that the lack of facets in the particle seen in Fig. 3 may be due to impurities in the starting materials or contamination in the furnace system a dedicated dewetting furnace was constructed, in which the specimen is held in a sapphire tube. Figure 4 presents HRSEM micrographs of a Ni particle equilibrated in $\mathrm{Ar}+\mathrm{H}_{2}$ (system $\left.\mathrm{C}, \mathrm{P}\left(\mathrm{O}_{2}\right)<10^{-20} \mathrm{~atm}\right)$ in the sapphire tube furnace. In addition, the Ni target used for the deposition was $99.9995 \%$ pure (rather than $99.99 \%$ as in systems A and B). The particle is oriented with the (111) plane parallel to the substrate surface, and appears to be completely faceted.

Unlike SEM, by which over 50 particles were found to have identical crystal shapes for the three annealing processes, cross-section imaging of the particles in the TEM allows improved resolution and facet identification by electron diffraction. However, specimen preparation requires extreme precision (about $20 \mathrm{~nm}$ tolerance in the location of the thinnest area) and provides only limited sampling (due to the time required for specimen preparation) of a single projection of the shape to be analyzed. In this work, three TEM specimens were characterized for system A, two for system B and 5 for system C. Figure 5- present bright field TEM micrographs of the equilibrated Ni particles. The specimens were prepared from the center of the same particles shown in Figure 2-Figure 3 respectively, along the directions marked on the plan-view SEM micrographs.

TEM analysis revealed that in the three systems, $\{111\},\{110\}$ and $\{100\}$ surface facets were stable. It should be noted that the existence of other facets cannot be ruled out since only one or two projections were examined for each system. In all cases, the lowest energy surface facets included both $\{111\}$ and $\{100\}$. Most facets have sharp edges which mean that some orientations are missing on the ECS. An exception is the 
$\{110\}$ facet on the particle equilibrated in system B (Figure 3). As observed from the SEM micrographs, this system also has the least anisotropic surface energy.

The use of a furnace with a sapphire tube and a purer Ni film (system C), stabilizes additional $\{113\}$ and $\{135\}$ surface facets that did not appear in the other two systems. The anisotropy for the examined particles as measured by TEM is given in Table 2 . The estimated measurement error is $2 \%$.

\section{ECS Simulations}

"Wulffman" freeware was used to identify all the facets present on the Wulff shape of the Ni particles, using the surface anisotropy observed by SEM (Table 2). The crystal equilibrium shape is approximated by a sphere cut by facets of given energy relative to the isotropic surface energy of the sphere. With this software we have identified the surface facets that are not included in the projection used for the specific TEM specimens, but are visible by SEM.

The Wulffman construction proved to be useful for system A, where two additional surface facets were identified: (012) and (013). Moreover, in system $\mathrm{C}$ the simulation proved that the $\{135\}$ facets are in fact included in the Wulff shape, and determined the presence of yet another vicinal surface, $\{138\}$, in the ECS. The $\{113\}$ facet that was identified by TEM is not present in the simulated ECS. This is because the surface plane that was thought to be (113) is not positioned edge-on in the TEM.

\section{Surface Chemistry}

APT was performed on the surface of particles with similar orientations to the ones analyzed by TEM. Line-scans are given for systems A, B (Figure 9, 10) and a 3D reconstructed tomogram is given for system $\mathrm{C}$ (Figure 11). Unlike in the case of liquid $\mathrm{Ni}$ equilibrated on sapphire [31], no Al was detected in the bulk Ni or at the surface (detection limit of 0.001 atoms $/ \mathrm{nm}^{2}$ which is roughly equivalent to 0.0001 monolayers).

For all three systems, a few nanometers thick layer of oxidized $\mathrm{Ni}$ was found at the surface. This is expected since the measurements were conducted an extended period of 
time after the samples were prepared using the FIB, which included transfer from the dewetting furnaces to the FIB, and to the APT system, during which surface oxidation could not be prevented. This issue is somewhat problematic and means that the measurement of oxygen at the surface is not possible. However, a major difference was measured in the bulk oxygen content for all 3 systems: 0.2 at $\%$ in system B, and less than 0.02 at $\%$ in system C. (The APT samples from system A were exposed to the ambient, as needles, for an extended duration and most of the metal was oxidized. Thus, the oxygen content in the Ni could not be determined for system A.) In system B, the surface Fe concentration was similar to that of the bulk (0.3-0.4at\%). It can be seen from Figure 11 that in system $\mathrm{C}$ no other element was detected other than $\mathrm{Ni}, \mathrm{O}$ and $\mathrm{C}$. Since the specimen was coated with a conductive carbon layer, no conclusions can be deduced regarding carbon surface adsorption.

\section{Solid-state dewetting kinetics}

It is clear from Figure 1 that most of the particles have not equilibrated under the experimental conditions used in this study. At the final stage of the experiment, the particles are all single-crystals with a $\{111\}$ plane parallel to the sapphire susbtrate. Although all of the facets that were identified in the ECS also appear in the large nonequilibrated particles, the particle aspect ratio is very large (they all have a height of 1$1.5 \mu \mathrm{m}$ regardless of the lateral dimensions). The particles that are less than $2 \mu \mathrm{m}$ in diameter seem to have equilibrated completely in the directions parallel to the substrate, while the top facet is larger than the equilibrium size. In Figure 12, three equi-axed particles are visible, with different diameters ranging from $1.02 \mu \mathrm{m}$ to $1.45 \mu \mathrm{m}$. The size of the side $\{111\}$ facets is marked by dashed lines to demonstrate that the top $\{111\}$ facet is larger, and hence not equilibrated for the particles shown in the center and bottom of Figure 12. However, the ratio of sizes measured for the side $\{111\}$ facets and the particle diameter is almost identical for all three particles, equal to 0.27 , indicating that the side facets had indeed reached a steady state which may be equilibrium.

\subsection{Discussion}




\section{Surface energy anisotropy}

The results presented here show that the crystal shape of pure Ni is completely faceted with a maximum anisotropy of $8 \%$, and does not include all orientations. Considering this shape as the ECS may be surprising because all ECS's of other FCC metals are spheroids truncated by small facets of two or three types of closed packed planes. Usually, an increase in surface anisotropy and the appearance of high index orientations are attributed to lower temperature, surface segregation, or surface structure (microscopic) reconstruction $[10,11]$.

Surface reconstruction: Since Ni has an absolute surface energy which is larger than most FCC metals, it is expected that the existence of a round surface that has a high number of unsaturated bonds (or a small number of nearest neighbors) will not be energetically favorable. This can result in a driving force for surface reconstruction that is larger than for other metals. Although it is known that Ni surface reconstruction occurs at room temperature, no reports were found in the literature about reconstruction above room temperature $[32,33]$.

Effect of temperature: In order to observe the Wulff shape of particles equilibrated at $0.97 \mathrm{Tm}$, the specimen must be cooled down very rapidly to prevent surface diffusion from changing the shape according to the temperature change. Unfortunately, in the present experimental apparatus rapid cooling cannot be done, and the specimens were cooled at a rate of $15 \mathrm{~K} / \mathrm{min}$. At this rate it took $36-40$ minutes to decrease the temperature to $0.6 \mathrm{Tm}$, where no significant diffusion is expected to occur. Such a cooling duration could have some influence on the final examined shape. However, since the cooling rate was the same for all three systems, the results can be a basis for comparison.

Surface composition: The fact that no impurities were detected on the surface of system $\mathrm{C}$ does not necessarily mean that this system represents the Wulff shape of clean Ni. First, atom probe analysis could not be used to quantify carbon or oxygen adsorption, due to specimen transfer/storage and the carbon coating used to prevent charging. Both carbon and oxygen are expected to influence surface anisotropy if they are present at the surface. Even if other impurities (like $\mathrm{S}$ which is a common impurity 
of Ni) were present at the initial stage of dewetting, and have evaporated, the surface still needs sufficient time to allow the crystal to re-equilibrate according to the new anisotropy (that of pure Ni). In the work by Chatain et al. [3], $\mathrm{Cu}$ films were dewetted in the liquid state and were equilibrated in the solid state under a reducing atmosphere. Impurities (such as sulfur) that were present in the initial film significantly increased the anisotropy and formed faceted steps around the larger facets. By equilibrating the particles under flowing $\mathrm{He}+\mathrm{H}_{2}$, the surface was cleaned of all impurities. However, it still took the crystals 78 hours to reshape into the new ECS (although the initial shape was very close to the final ECS of pure $\mathrm{Cu}$ ).

Shape equilibration: Shape evolution towards equilibrium depends upon the initial state of the system. If the initial shape was a sphere (as in the case of solidifying drop), it is expected to develop facets that will increase in size at the expense of the rounded surfaces. In the case of growth shapes (as in solid state dewetting), a polyhedral crystal will form during the initial stages of dewetting and the rounded surfaces will only develop at the final stages of equilibration. In the present work, it is possible that the fully faceted $\mathrm{Ni}$ crystals represent growth shapes rather than an equilibrium shape. However, while impurities and kinetic effects may have prevented full equilibration in these experiments, we think that system $\mathrm{C}$ is the closest to equilibrium for the following reasons:

a) In contrast to previous equilibration experiments of $\mathrm{Cu}$, it is less likely that impurities originated from the Ni target (which was $99.9995 \%$ pure for systems B and C). Impurities may have come from the sapphire substrate $(99.99 \%$, probably containing several ppm of $\mathrm{Na}, \mathrm{Ca}, \mathrm{Si}$ ), but these were not detected by APT.

b) The very long equilibration times required for $\mathrm{Cu}$ was for particles that were about $5 \mu \mathrm{m}$ in diameter. According to equation (3), the time for shape equilibration depends very strongly on the particle size, and the sub-micron Ni particles are expected to have reached equilibration.

c) Since the present experiment was done in the solid state, equilibration kinetics and their mechanisms are quite different than the ones proposed by Nichols and Mullins [27] and Mullins and Rohrer [34,35]. In their models, shape changes are calculated for surface-diffusion processes on particles that are initially spherical, and develop facets that are tangentially connected to the neighboring vicinal orientations. 
Whereas in this work, where the initial geometry is a flat continuous film, the facets have mostly sharp edges, and evaporation-condensation is also expected to take part in mass transport. To the best of our knowledge, no model has been formulated to describe the time required to equilibrate solid particles similar to the ones seen in this work.

\section{Simulations of the equilibrium shape:}

Although the facets and their relative stability identified by TEM agree very well with those calculated using Wulffman, several discrepancies were found in the relative surface energies of the stable facets. In system $A$, the relative energy of the $\{100\}$ facet is lower than the measured value (see Table 2). The reason for this is that the top (100) facet that was used to determine the relative energy is slightly larger than the side $\{100\}$ facets. In other words, the top facet hadn't fully reached its equilibrium size. The projection chosen for TEM analysis does not include the side $\{100\}$ facets, and thus this error in measurement could not be considered. However, the shape simulation did include the projected size of the side facets (seen from the top view in Figure 2 and Figure 8a). Hence, for system A, the calculated anisotropy is more correct than the measured one. The calculated anisotropy for system $\mathrm{C}$ is lower for almost all facets. The reason for this is that the size of the $\{111\}$ facets in the simulation is smaller than the real size of these facets (i.e., it is thought to have a larger relative energy). Since all energies in Table 2 were taken relative to that of $\{111\}$, the resulting values reflect a lower anisotropy. Thus, for system $\mathrm{C}$, the experimental measurement (as conducted using TEM) is more accurate than the simulation.

\section{Effect of $P\left(\mathrm{O}_{2}\right)$ and $\mathrm{Fe}$ contamination}

It is clear that the dominant factor that determines the anisotropy is different in all three systems. In system A, it is believed that the main factor is the presence of a larger amount of oxygen in the gas phase. In system B, Fe is the dominant factor, although it may be a combined effect with oxygen. According to the APT profile, the Fe concentration at the surface is similar to that of the bulk, i.e., there is no Fe surface segregation. This is explained by the similar surface energies of Fe and $\mathrm{Ni}\left(\gamma_{\mathrm{Fe}}\right.$ is 
slightly higher) and the relatively large enthalpy of mixing [18]. Although the influence of $\mathrm{Fe}$ on the surface anisotropy is dramatic, it is not clear what lowers the surface energy of rough surfaces and de-stabilizes higher index planes. One possible explanation is the formation of $\mathrm{Fe}-\mathrm{O}$ bonds at the surface. In System $\mathrm{C}$, the main reason for the high anisotropy and the stability of high index planes was discussed above.

\section{Shape Equilibration Kinetics}

In order to satisfy the size limitation for shape equilibration according to equation (3), all of the examined particles were less than $1 \mu \mathrm{m}$ in diameter. However, for some particles that did meet this requirement, the aspect ratio did not reach that of equilibrium. It should be noted that equation (3) considers only surface diffusion and no other processes such as evaporation-condensation that may also take part in equilibration, especially at such high homologous temperatures. According to Mullins and Rohrer $[34,35]$ in order for a facet to reach an equilibrium size, a nucleation energy barrier needs to be overcome to create a step on the surface. This approach applies to the case where mass transport occurs only by surface diffusion and the facet has no step-propagating defects such as screw dislocations or discontinuous facet edges (no tangential connection between the facet and the adjacent surface orientations).

\subsection{Summary \& Conclusions}

Solid-state dewetting experiments of pure and Fe-doped Ni films were performed under controlled working conditions. The crystal shape was analyzed by three complementary characterization methods (SEM, TEM and Wulffman simulations), and for the first time the nickel crystal shape was related to the chemical composition of the surface. The crystal shape was found almost completely facetted with both dense and high index planes, in contrast to that expected for an FCC metal. At $\mathrm{P}\left(\mathrm{O}_{2}\right)=1 * 10^{-9}$ atm, $\{012\}$ and $\{013\}$ facets were stabilized, and at $\mathrm{P}\left(\mathrm{O}_{2}\right)<1 * 10^{-20}$ atm, $\{135\}$ and $\{138\}$ facets were stabilized. The addition of Fe decreased the anisotropy dramatically, de-stabilizing highindex planes. The kinetics of particle shape equilibration from the geometry of a thin film was studied. A major difference was found between shape evolution in the 
directions parallel and normal to the substrate. This resulted in particles that had side facets with similar proportions (i.e., the same facet diameter to particle diameter ratio) but a top facet that is significantly larger, indicating a nucleation barrier preventing the top facet from reaching equilibrium.

\section{Appendix I - P( $\left(\mathrm{O}_{2}\right)$ Measurements}

In the experimental apparatus used for systems B and C, the partial pressure of oxygen was controlled by the reaction: $\mathrm{O}_{2}+2 \mathrm{H}_{2} \rightarrow 2 \mathrm{H}_{2} \mathrm{O}$. The specimen was placed in a sapphire tube furnace under flowing $\mathrm{Ar}+7 \% \mathrm{vol} . \mathrm{H}_{2}$. Since the total pressure was $1 \mathrm{~atm}$, the $\mathrm{P}\left(\mathrm{H}_{2}\right)=0.07 \mathrm{~atm}$.

The moisture content in the gas tank (as measured by the manufacturer) is $0.1 \mathrm{ppm}$. Assuming the moisture level in the chamber is 1 ppm gives a $\mathrm{P}\left(\mathrm{H}_{2} \mathrm{O}\right)$ of $1 * 10^{-6}$ atm.

The $\mathrm{P}\left(\mathrm{O}_{2}\right)$ can then be calculated using:

$$
\Delta G=-R T \ln \left[\frac{P\left(\mathrm{H}_{2} \mathrm{O}\right)^{2}}{P\left(\mathrm{H}_{2}\right)^{2} P\left(\mathrm{O}_{2}\right)}\right]
$$

At $\mathrm{T}=1623 \mathrm{~K}, \Delta \mathrm{G}=-313500 \mathrm{~J} / \mathrm{mol}$, giving a $\mathrm{P}\left(\mathrm{O}_{2}\right)=1.6 * 10^{-20} \mathrm{~atm}$.

\section{Appendix II - Estimation of the Absolute Solid Surface Energy of Ni}

In addition to relative surface energy and thus anisotropy, the data given in the present study was used to estimate the absolute surface free energy of solid Ni. This is an extremely important and fundamental parameter that is rarely measured due to the lack of a rigorous experimental method. In this work, we estimated the solid surface energy using several assumptions and data from the literature:

a) Levitated drop experiments by Brillo et al. [18] were used to obtain the surface energy of undercooled liquid $\mathrm{Ni}$ at $1625 \mathrm{~K}$. They used the same Ni as used for the dewetting experiments. From the measurements we obtained $\gamma_{(\text {liquid,1625K) }}=1.8$ $\mathrm{J} / \mathrm{m}^{2}$. 
b) Considering a $2 \%$ increase in surface energy at solidification [36] (due to the solid-liquid interface that is formed) gives $\gamma_{(\text {solid,1625K) }}=2.16 \mathrm{~J} / \mathrm{m}^{2}$. This value represents the surface free energy of the rounded solid surface.

c) Taking into account the measured surface anisotropy $\gamma_{(\{111\}, 1625 \mathrm{~K})}=2.05 \pm 0.05$ $\mathrm{J} / \mathrm{m}^{2}$.

The major assumption in this approach is the $20 \%$ increase in surface energy upon solidification, while the advantage is that absolute values of surface energy can be determined for each individual facet. Zero creep experiments can provide a direct measurement of the average solid surface energy, and Kumikov and Khokonov suggest that the most reliable published value for the average surface energy of $\mathrm{Ni}$ is $1.94 \mathrm{~J} / \mathrm{m}^{2}$ [37], which is close to the value measured here.

\section{Acknowledgements}

The authors gratefully acknowledge P. Wynblatt for enlightening discussions. The United States - Israel Binational Science Foundation (BSF Grant 2004068) and the Russell Berrie Nanotechnology Institute at the Technion are acknowledged for partial support of this study. Evan Ohriner of ORNL is thanked for providing high purity Ni target material. HM acknowledges support from the Women in Science program of the Israel Ministry of Science and an Ilan Ramon scholarship. DC and WDK acknowledge partial support from the Ministry of Science \& Technology, Israel and the Ministry of Research, France. This document has been produced with the partial financial assistance of the European Union as part of the MACAN project as part of the Seventh Framework Programme (2007 - 2013) under grant agreement FP7-NMP-2009-CSA-233484.

\section{References}

1. Wulff G. Z. Krystallogr. Mineral. 1901;34:449.

2. Cuire P. Bull. Soc. Fr. Min. Crist. 1885;8:145

3. Chatain D, Ghetta V, Wynblatt P. Interface Science 2004;12:7. 
4. Sundquist BE. Acta Metallurgica 1964;12:67.

5 Emundts A, Bonzel HP, Wynblatt P, Thurmer K, Reutt-Robey J, Williams ED. Surface Science 2001;481:13.

6 Heyraud JC, Metois JJ. Surface Science 1983;128:334.

7. Wang ZM, Wynblatt P. Surface Science 1998;398:259.

8. Heyraud JC, Metois JJ. Acta Metallurgica 1980;28:1789.

9 Heyraud JC, Métois JJ. Journal of Crystal Growth 1987;82:269.

10 Chatain D. Annu. Rev. Mater. Res. 2008;38:45.

11. Chatain D, Wynblatt P, Rohrer GS. Acta Materialia 2005;53:4057.

12. Wynblatt P, Chatain D. Reviews on Advanced Materials Science 2009;21:44.

13 Hondros ED, McLean M. In: Structures et Propriétés des Surfaces, (Editions du CNRS: Paris, 1970), p. 219.

14 Cheng W-C, Wynblatt P. Journal of Crystal Growth 1997;173:513.

15 Ghetta V, Fouletier J, Chatain D. Acta Materialia 1996;44:1927.

16 Serre C, Wynblatt P, Chatain D. Surface Science 1998;415:336.

17 Shim H, Chatain D, Wynblatt P. Surface Science 1998;415:346.

18. Brillo J, Egry I. Journal of Materials Science 2005;40:2213

19 Hong JS, Jo W, Ko KJ, Hwang NM, Kim DY. Philosophical Magazine: 2009;89:2989.

20. Mykura H. Acta Metallurgica; 1961;9:570

21 Hanbicki AT, Darling SB, Gaspar DJ, Sibener SJ. The Journal of Chemical Physics 1999;111:9053.

22. Barsotti T. Bermond JM. Drechsler M. Journal de Physique, Colloque 1984;C9:43.

23. Levi G, Kaplan WD. Acta Materialia 2003;51:2793.

24 Trumble KP, Ruhle M. Acta Metallurgica Et Materialia 1991;39:1915.

25. Reyntjens S. and Puers R., Journal of Micromechanics and Microengineering 2001;11:287.

26 Sadan H, Kaplan WD, Journal of Materials Science 2006;41:5099.

27. Nichols FA. Mullins WW. Transactions of the American Institute of Mining, Metallurgical and Petroleum Engineers, 1965;233[10]:1840. 
28. Gal VV, Gruzin PL, Yudina GK. Physica Status Solidi A: Applied Research 1973;15:659.

29. Roosen AR, McCormack RP, Carter WC. Computational Materials Science 1998;11:16.

30. Meltzman H, Kauffmann Y, Thangadurai P, Drozdov M, Baram M, Brandon D, Kaplan WD. Journal of Microscopy 2009;236:165.

31. Levi G, Clarke DR, Kaplan WD. Interface Science 2004;12:73.

32. Kaukasoina P, Lindroos M, Diehl RD, Fisher D, Chandavarkar S, Collins IR. Journal of Physics: Condensed Matter 1993;5:2875.

33. Thurgate SM, Jennings PJ. Applications of Surface Science 1985;22-23:478.

34. Mullins WW, Rohrer GS, Journal of the American Ceramic Society 2000;83 (1):214.

35. Rohrer GS, Rohrer CL, Mullins WW. Journal of the American Ceramic Society 2001;84(9):2099.

36. Howe JM. International Materials Reviews 1993;38:233.

37. Kumikov VK, Khokonov KB. Journal of Applied Physics 1983;54:1346. 


\section{Tables \& Captions}

Table 1: Experimental conditions used to equilibrate the Ni particles.

\begin{tabular}{|c|c|c|c|c|c|c|}
\hline System & $\begin{array}{l}\text { Atmosphere } \\
\text { (dynamic flow) }\end{array}$ & $\begin{array}{l}\text { Deposition } \\
\text { Method } \\
\text { (Ni purity) }\end{array}$ & $\begin{array}{l}\text { Measured } \\
\mathrm{P}\left(\mathrm{O}_{2}\right)[\mathrm{atm}]\end{array}$ & $\begin{array}{l}\text { Annealing } \\
\text { temperature }\end{array}$ & $\begin{array}{l}\text { Time at } \\
\text { temperature }\end{array}$ & Texture \\
\hline $\mathbf{A}$ & $\mathrm{Ar}$ & $\begin{array}{l}\text { Sputtering } \\
(99.99 \%)\end{array}$ & $1 * 10^{-9}$ & $1300^{\circ} \mathrm{C}$ & 30 minutes & $\{100\}$ \\
\hline B & $\begin{array}{c}\mathrm{Ar}+7 \mathrm{vol} . \% \mathrm{H}_{2} \\
\left(+\mathrm{Fe}^{*}\right)\end{array}$ & $\begin{array}{l}\text { Sputtering } \\
(99.99 \%)\end{array}$ & $<10^{-20}$ & $1350^{\circ} \mathrm{C}$ & 120 minutes & $\{111\}$ \\
\hline $\mathbf{C}$ & $\mathrm{Ar}+7 \mathrm{vol} . \% \mathrm{H}_{2}$ & $\begin{array}{l}\text { e-beam deposition } \\
(99.9995 \%)\end{array}$ & $<10^{-20}$ & $1350^{\circ} \mathrm{C}$ & 300 minutes & $\{111\}$ \\
\hline
\end{tabular}

Table 2: Ni surface energy anisotropy as measured by TEM or from "Wulffman" simulations.

\begin{tabular}{|c|c|c|c|c|c|c|c|c|}
\hline \multirow{2}{*}{ System } & \multirow{2}{*}{$\mathbf{P}\left(\mathbf{O}_{2}\right)$} & \multicolumn{7}{|c|}{$\begin{array}{l}\text { Relative surface energies, } \gamma_{(\mathrm{hkl})} / \gamma_{(111)} \\
\text { as measured by TEM (red) or by Wulffman (blue) }\end{array}$} \\
\hline & & $\gamma_{(001)}$ & $\gamma_{(011)}$ & $\gamma_{(012)}$ & $\gamma_{(013)}$ & $\gamma_{(\mathbf{1 3 5})}$ & $\gamma_{(\mathbf{1 3 8})}$ & $\gamma_{(\max )}$ \\
\hline \multirow{2}{*}{ A } & \multirow{2}{*}{$10^{-9} \mathrm{~atm}$} & 1 & 1.05 & & & & & 1.07 \\
\hline & & 1.05 & 1.05 & 1.05 & 1.05 & & & 1.06 \\
\hline \multirow{2}{*}{ B } & \multirow{2}{*}{$10^{-20} \mathrm{~atm}$} & 1 & 1.01 & & & & & 1.05 \\
\hline & & 1 & 1.01 & & & & & 1.05 \\
\hline \multirow{2}{*}{ C } & \multirow{2}{*}{$10^{-20} \mathrm{~atm}$} & 1 & 1.06 & & & 1.04 & & 1.08 \\
\hline & & 1.02 & 1.03 & & & 1.01 & 1.03 & 1.04 \\
\hline
\end{tabular}

\footnotetext{
${ }^{*}$ The furnace used in system B was contaminated with $\mathrm{Fe}$.
} 


\section{Figure Captions}

Figure 1: Ni particles after dewetting on (0001) sapphire for 5 hours at $1623 \mathrm{~K}$ in $\mathrm{Ar}+7 \% \mathrm{H}_{2}$.

Figure 2: Secondary electron HRSEM micrographs of a $\mathrm{Ni}$ particle (system A, $\left.\mathrm{P}\left(\mathrm{O}_{2}\right)=1 * 10^{-9} \mathrm{~atm}\right)$. The single crystal particle is oriented with the (100) plane parallel to the substrate. (a) plan-view. (b) side-view ( $52^{\circ}$ tilt). The arrows indicate the location and direction of sectioning.

Figure 3: Secondary electron HRSEM micrographs of a $\mathrm{Ni}$ particle in system $\mathrm{B}$ $\left(\mathrm{P}\left(\mathrm{O}_{2}\right)=10^{-20} \mathrm{~atm}\right)$. The single crystal particle is oriented with the (111) plane parallel to the substrate surface. (a) plan-view (b) side-view (52 tilt). The arrows indicate the location and direction of sectioning. The bright contrast in (b) is due to electron charging of uncoated sapphire.

Figure 4: HRSEM micrographs of a Ni particle from system $\mathrm{C}\left(\mathrm{P}\left(\mathrm{O}_{2}\right)=10^{-20} \mathrm{~atm}\right)$. The single-crystal particle is oriented with the (111) plane parallel to the substrate surface. (a) plan-view (b) side-view (52 tilt). The arrows indicate the locations and directions of sectioning.

Figure 5: (a) bright field TEM micrograph of the (100) oriented Ni particle in system A along the [101] projection. (b) The Wulff shape contour (bold line), selected area electron diffraction pattern (inset in the center) and distances from the Wulff point to the $\{\mathrm{hkl}\}$ facets (dotted lines, marked as $\mathrm{R}\{\mathrm{hkl}\}$ ).

Figure 6: (a) High angle annular dark field STEM micrographs of the (111) oriented Ni particle equilibrated in system B, along the [101] projection. (b) The Wulff shape contour (bold line), selected area electron diffraction pattern (inset in the center) and distances from the Wulff point to the $\{h k l\}$ facets (dotted lines, marked as $\mathrm{R}\{\mathrm{hkl}\}$ ).

Figure 7: (a,c) bright field TEM micrographs of the (111) oriented Ni particle equilibrated in system $C$, along the [101] and [121] projections. (b,d) The Wulff shape 
contour (bold line), selected area electron diffraction patterns (inset in the center) and distances from the Wulff point to the $\{h k l\}$ facets (dashed lines, marked as $\mathrm{R}\{\mathrm{hkl}\}$ ).

Figure 8: "Wulffman" simulations from SEM pictures of the ECS of particles from systems A, B and C.

Figure 9: Line-scan from the APT data perpendicular to the Ni surface from system B.

Figure 10: Line-scan from the APT data perpendicular to the Ni surface from system A.

Figure 11: Reconstructed atom probe tomogram of the top of a (111) Ni particle from system C. Only three elements were detected: $\mathrm{Ni}, \mathrm{O}$ and $\mathrm{C}$. The large blue circles represent oxygen adsorbed from the ambient on the surface of the atom probe tip (after sample preparation).

Figure 12: SEM micrographs of three particles of different diameters in system C showing different stages of equilibration. The dotted lines mark the size of the $\{111\}$ facets on the sides, for comparison with the top $\{111\}$ facet. Only the top particle reached equilibrium. All three particles exhibit the same facets but different relative size of the top $\{111\}$ facet. 


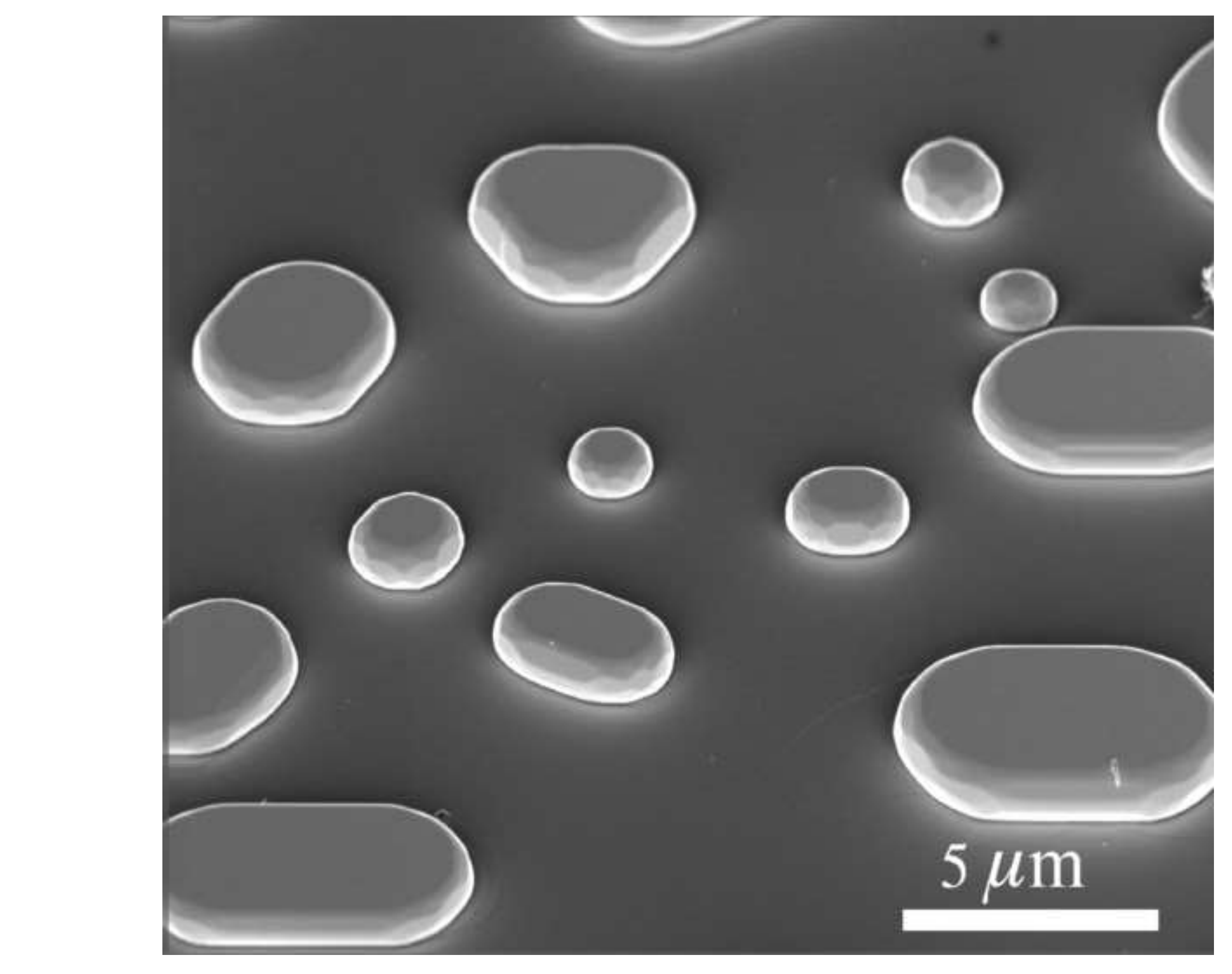

Figure-1
Click here to download high resolution image

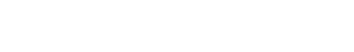


Click here to download high resolution image

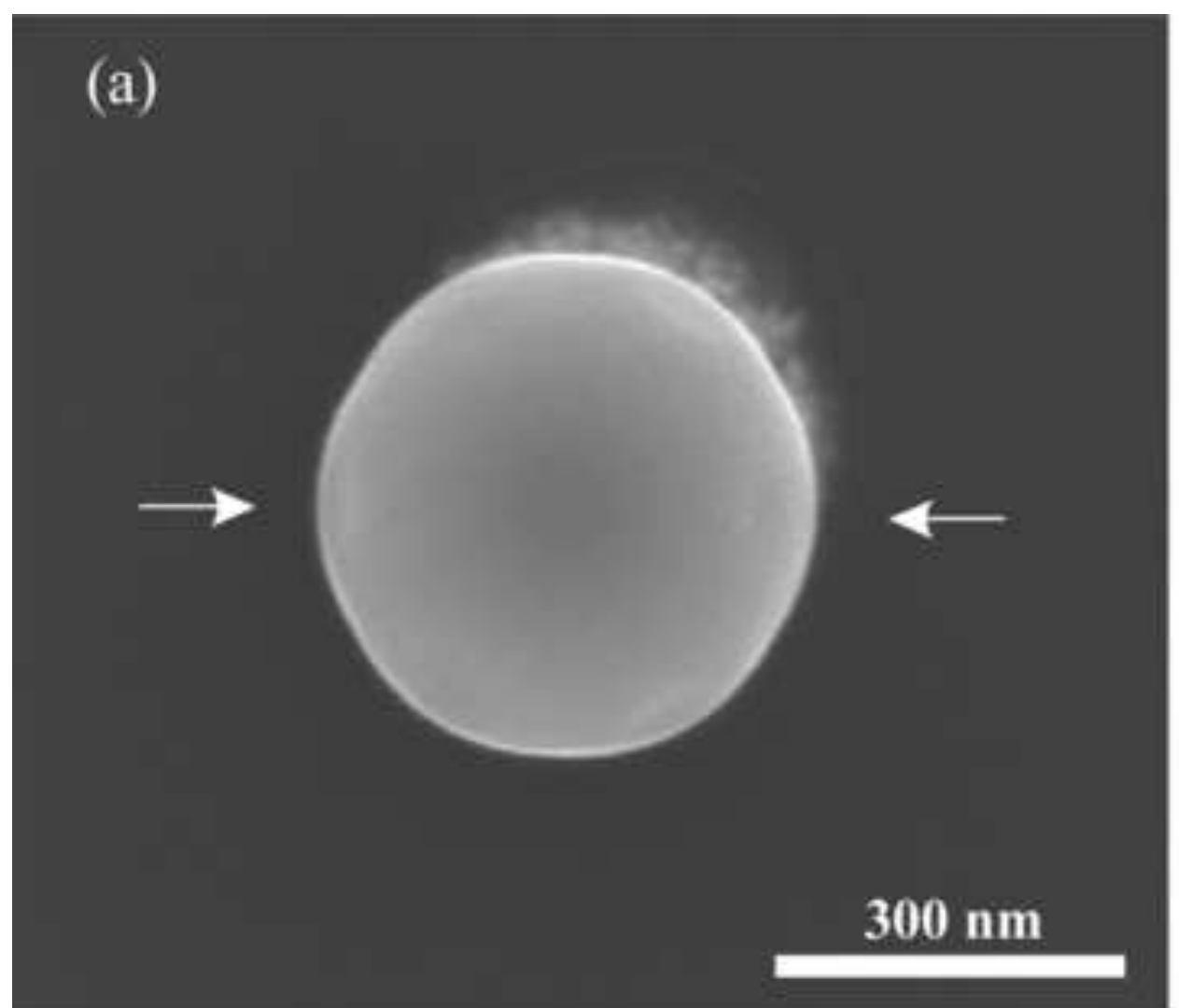

(b) 
Click here to download high resolution image
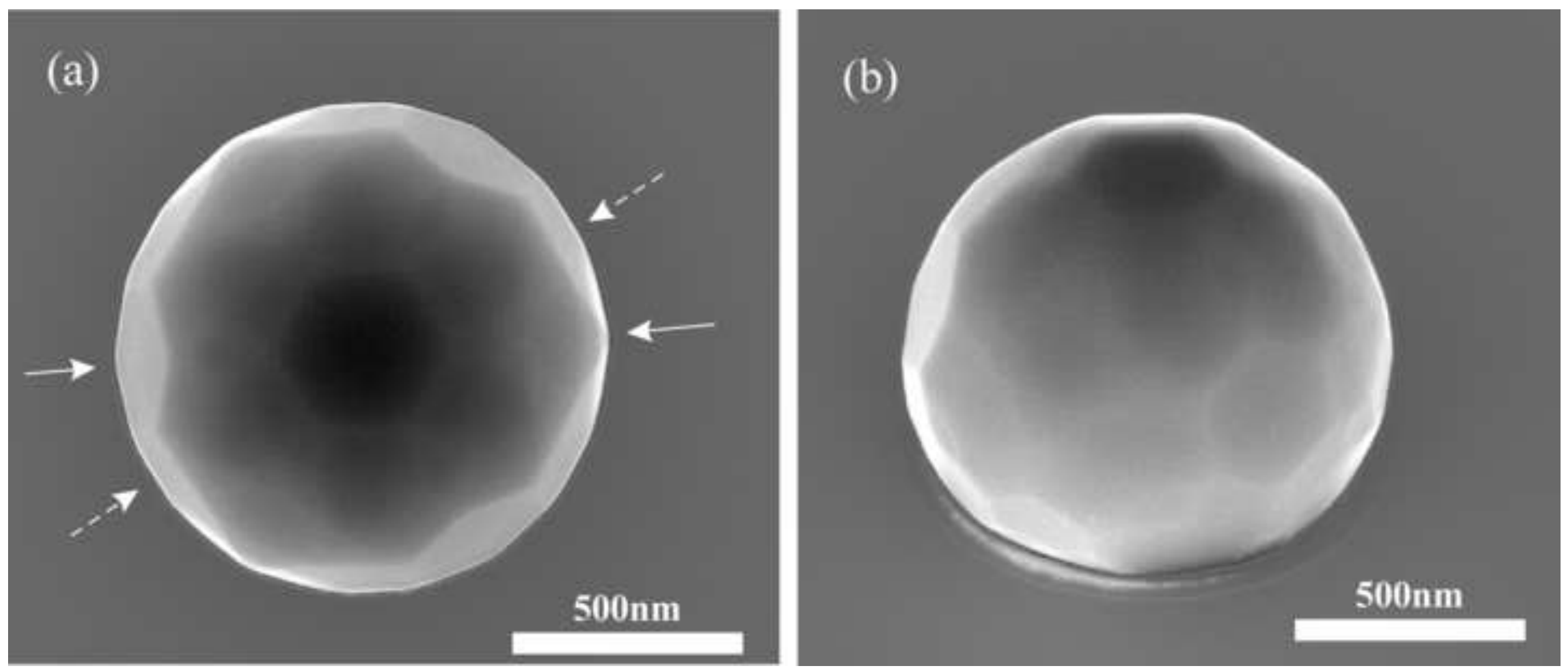

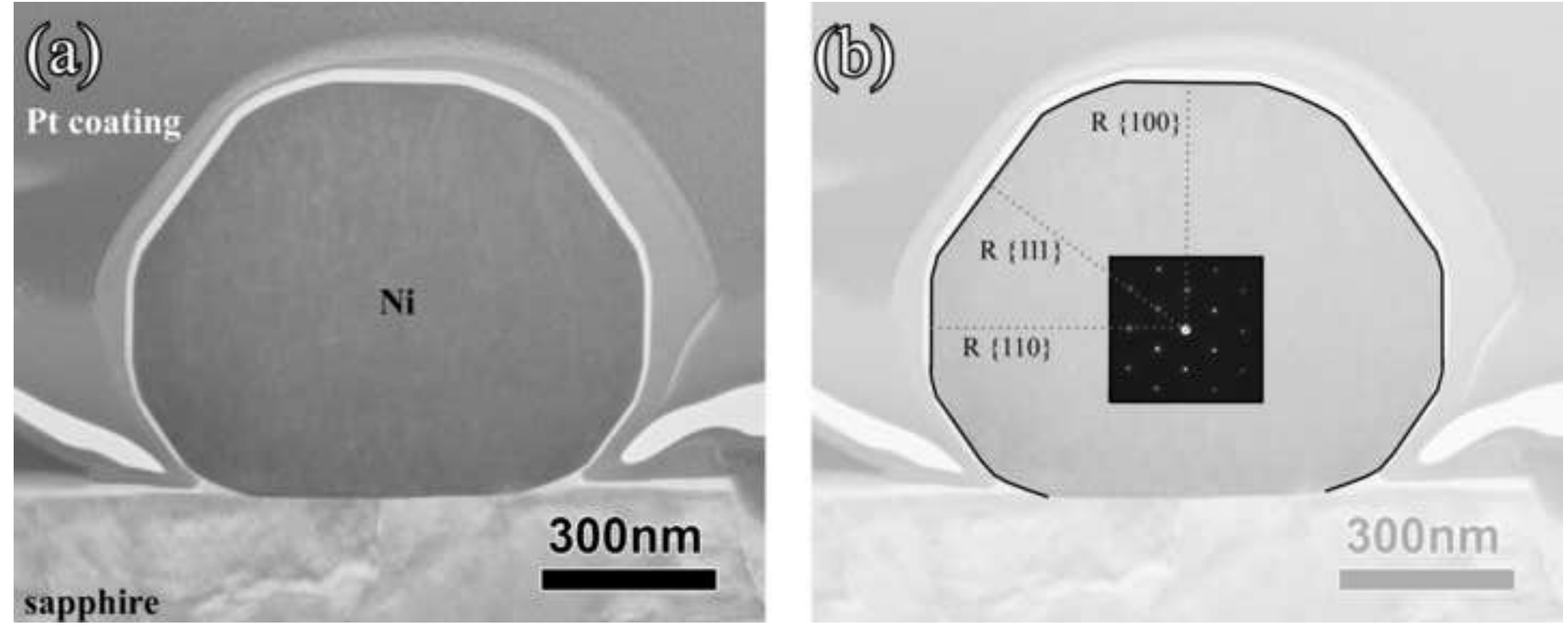
Click here to download high resolution image
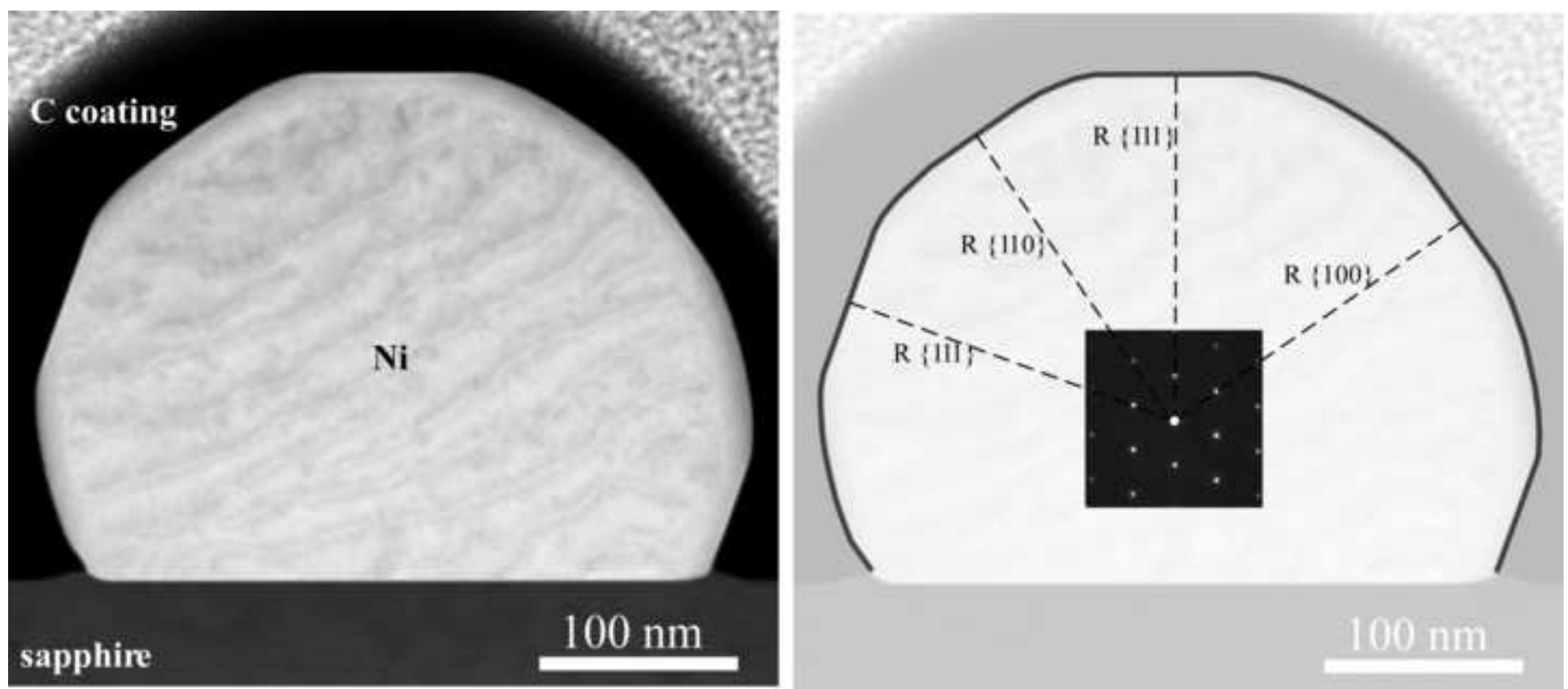
Figure-7
Click here to download high resolution image
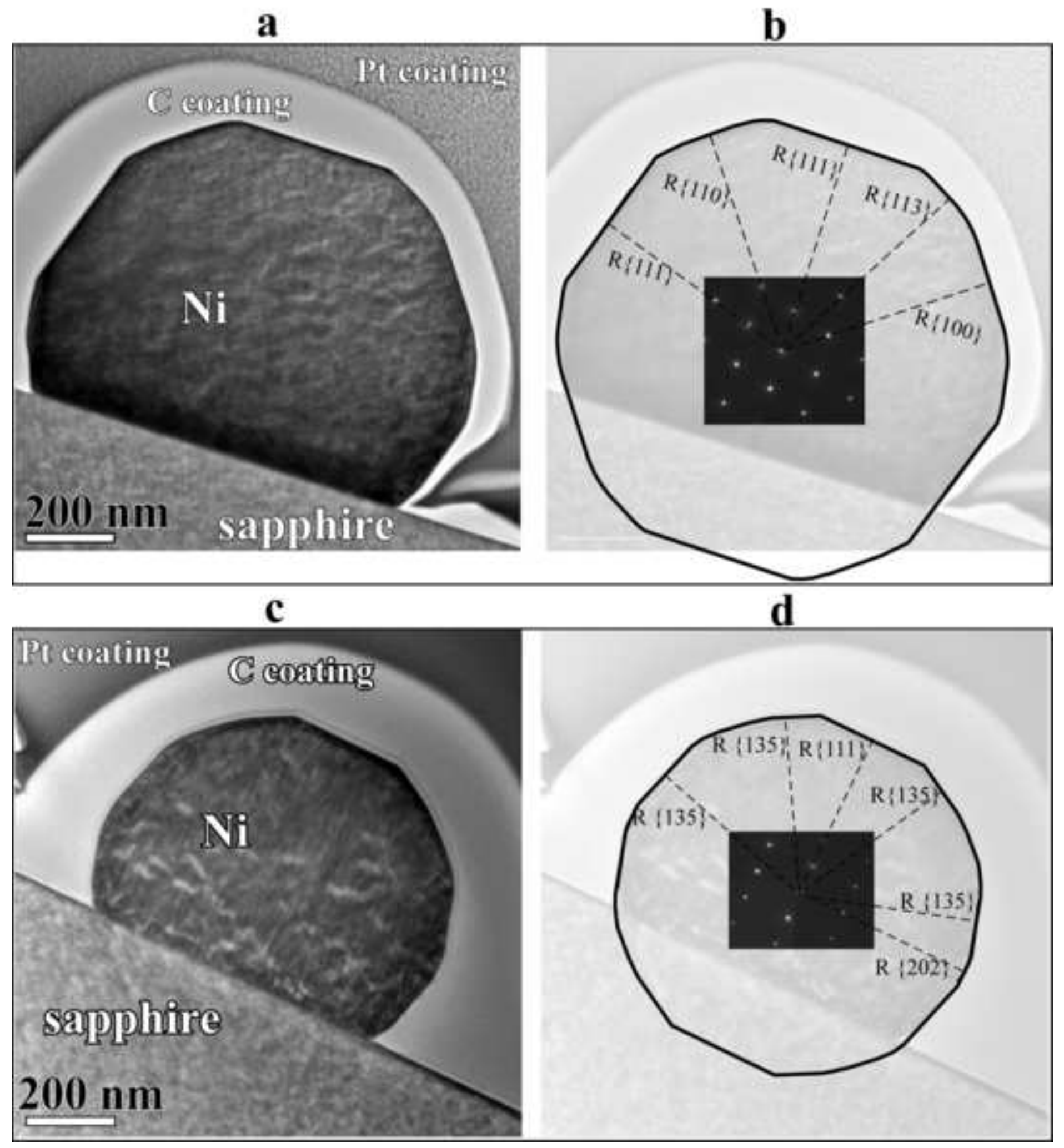

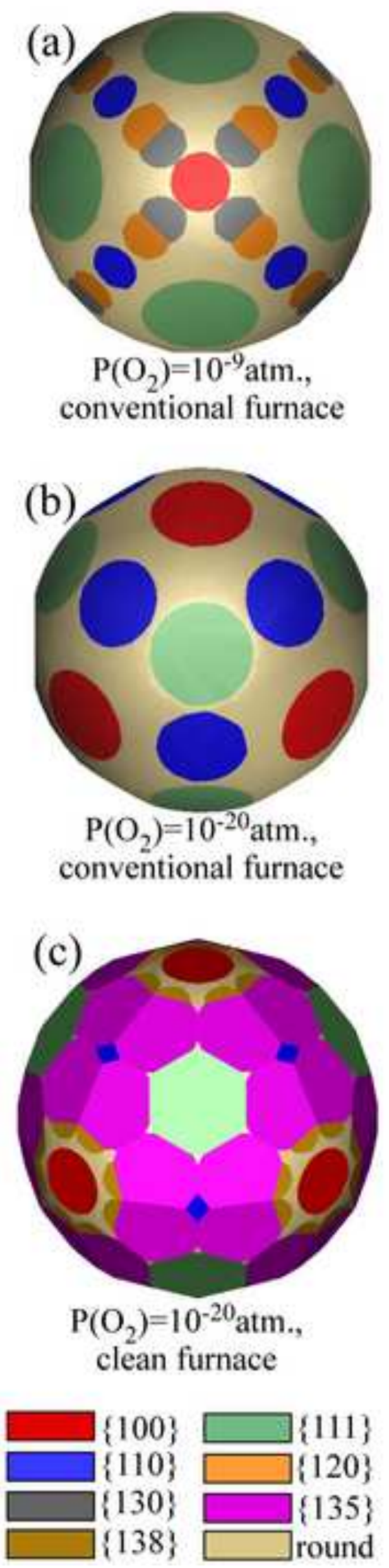


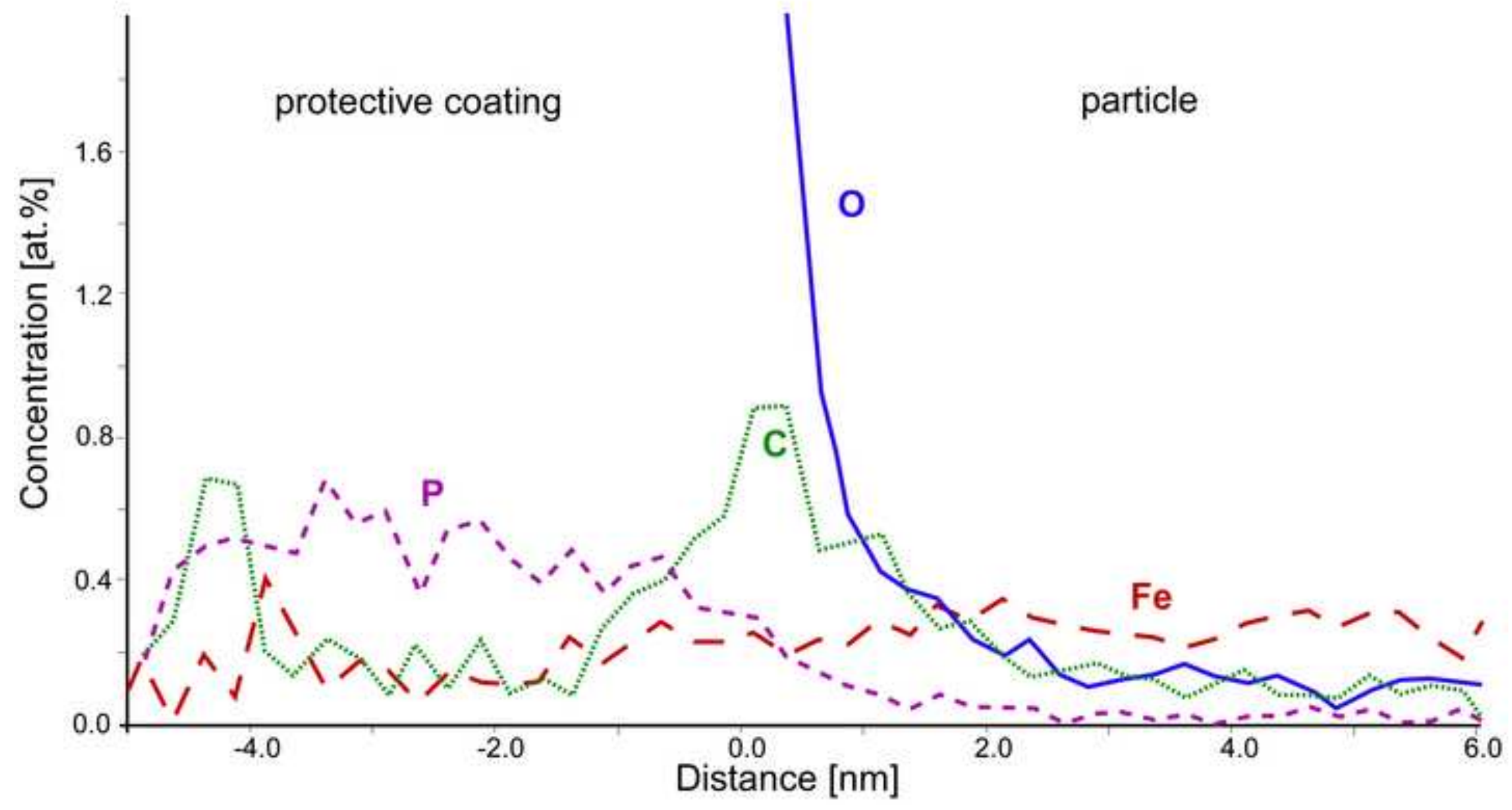


Click here to download high resolution image

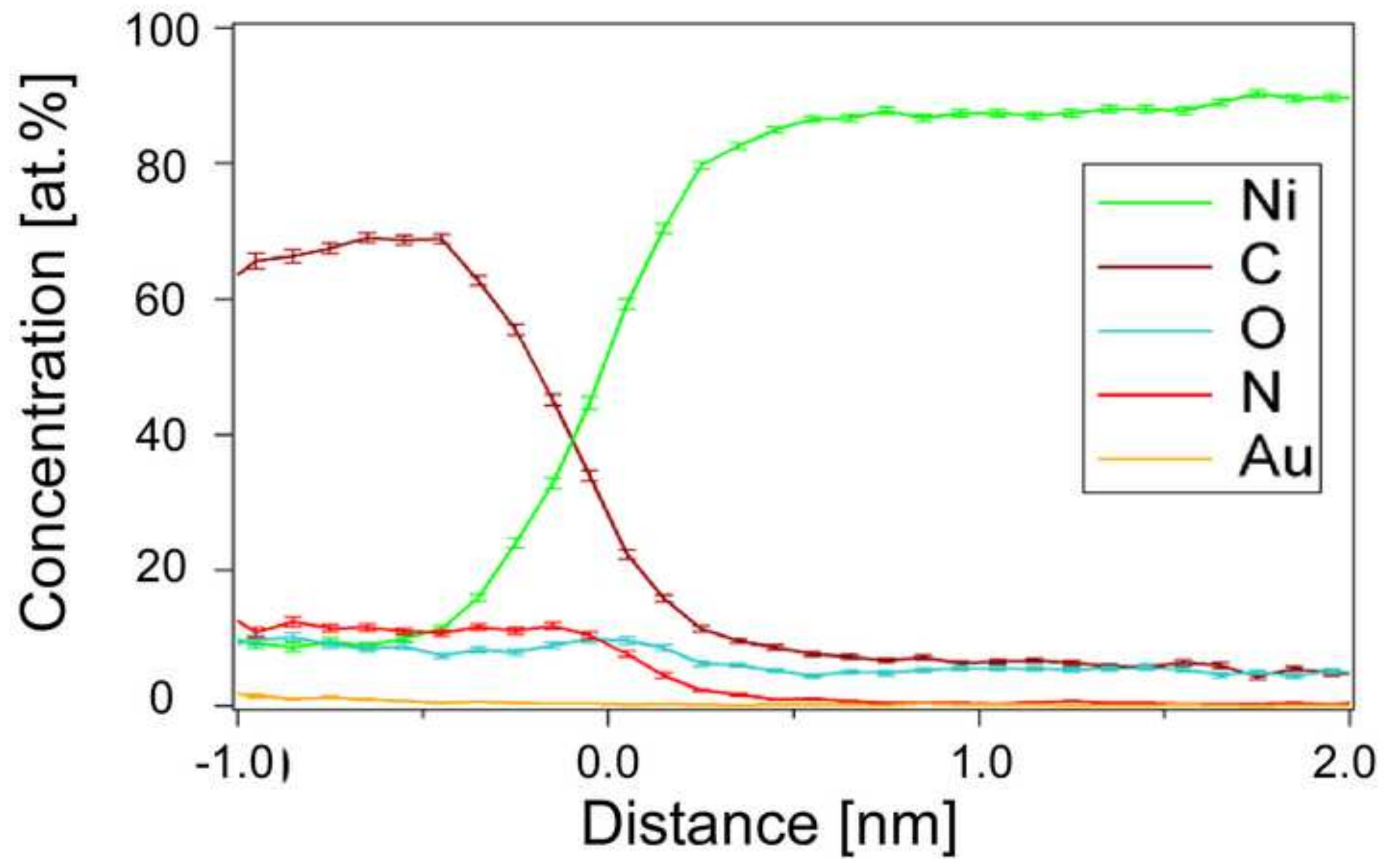




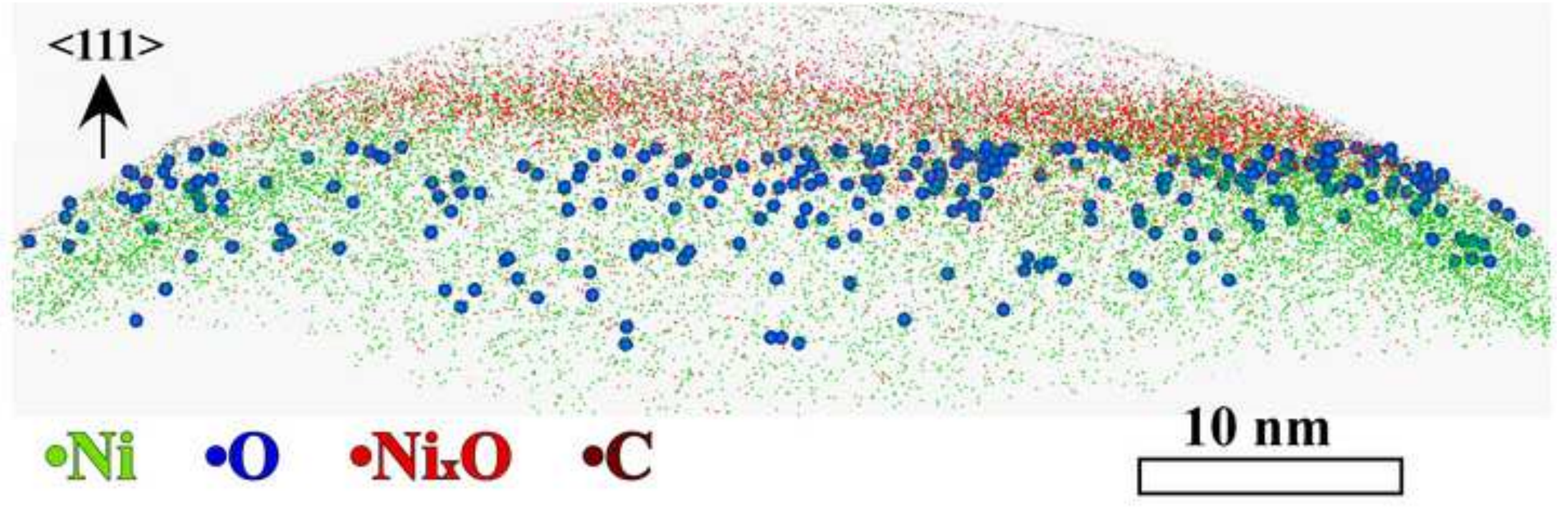




\section{Figure-12}

Click here to download high resolution image

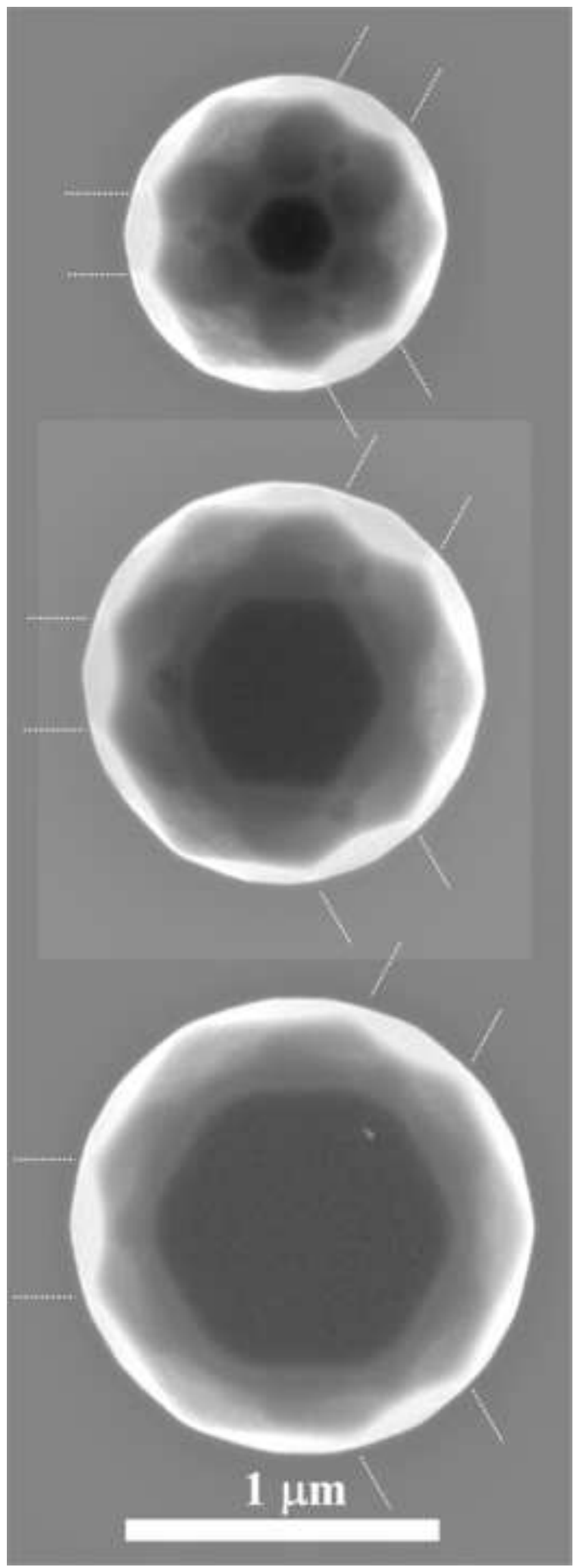

